\title{
Targeting androgen receptor (AR) with antiandrogen Enzalutamide increases prostate cancer cell invasion yet decreases bladder cancer cell invasion via differentially altering the $A R /$ circRNA-ARC1/miR- 125b-2-3p or miR-4736/PPARy/MMP-9 signals
}

\author{
Gang Deng ${ }^{1,2} \cdot$ Ronghao Wang ${ }^{2,3} \cdot$ Yin Sun $^{2} \cdot$ Chi-Ping Huang $\mathbb{D}^{4} \cdot$ Shuyuan Yeh $\mathbb{D}^{2} \cdot$ Bosen You ${ }^{2} \cdot$ \\ Changyong Feng ${ }^{5} \cdot$ Gonghui $\mathrm{Li}^{2} \cdot$ Shenglin $\mathrm{Ma}^{1} \cdot$ Chawnshang Chang ${ }^{2,4}$
}

Received: 12 August 2019 / Revised: 20 January 2021 / Accepted: 22 January 2021 / Published online: 14 June 2021

(c) The Author(s) 2021. This article is published with open access

\begin{abstract}
Androgen-deprivation therapy (ADT) via targeting androgens/androgen receptor (AR) signals may suppress cell proliferation in both prostate cancer $(\mathrm{PCa})$ and bladder cancer $(\mathrm{BCa})$, yet its impact on the cell invasion of these two urological cancers remains unclear. Here we found targeting androgens/AR with either the recently developed antiandrogen Enzalutamide (Enz) or AR-shRNAs led to increase PCa cell invasion, yet decrease BCa cell invasion. Mechanistic dissection revealed that suppressing androgens/AR signals could result in differential alterations of the selective circular RNAs (circRNAs) as a result of differential endogenous AR transcription. A negative autoregulation in $\mathrm{PCa}$, yet a positive autoregulation in $\mathrm{BCa}$, as a result of differential binding of AR to different androgen-response elements (AREs) and a discriminating histone H3K4 methylation, likely contributes to this outcome between these two urological tumors. Further mechanistic studies indicated that AR-encoded circRNA-ARC1 might sponge/alter the availability of the miRNAs miR-125b-2-3p and/or miR-4736, to impact the metastasisrelated PPAR $\gamma / \mathrm{MMP}-9$ signals to alter the PCa vs. BCa cell invasion. The preclinical study using the in vivo mouse model confirms in vitro cell lines data, showing that Enz treatment could increase PCa metastasis, which can be suppressed after suppressing circRNA-ARC1 with sh-circRNA-ARC1. Together, these in vitro/in vivo results demonstrate that antiandrogen therapy with Enz via targeting AR may lead to either increase PCa cell invasion or decrease BCa cell invasion. Targeting these newly identified AR/circRNA-ARC1/miR-125b-2-3p and/or miR-4736/PPAR $\gamma /$ MMP-9 signals may help in the development of new therapies to better suppress the Enz-altered PCa vs. BCa metastasis.
\end{abstract}

These authors contributed equally: Gang Deng, Ronghao Wang, Yin Sun, Chi-Ping Huang

These authors jointly supervised this work: Shenglin Ma, Chawnshang Chang

Edited by H. Ichijo

Supplementary information The online version contains supplementary material available at https://doi.org/10.1038/s41418021-00743-w.

Shenglin $\mathrm{Ma}$

mashenglin@medmail.com.cn

$\triangle$ Chawnshang Chang

chang@urmc.rochester.edu

1 Department of Urology, Affiliated Hangzhou First People's Hospital, Zhejiang University School of Medicine,

Hangzhou, China

2 George Whipple Lab for Cancer Research, Departments of Pathology, Urology, Radiation Oncology and The Wilmot Cancer

\section{Introduction}

While the androgen receptor (AR) may play key roles to increase the tumor cell proliferation in several sex hormonerelated tumors including prostate [1-6], bladder [7, 8], kidney [9, 10], breast [11], and liver [12-14], its impact on tumor cell invasion remains varied, as recent studies indicated that AR might function as a suppressor to decrease

Institute, University of Rochester Medical Center, Rochester, NY, USA

3 Department of Biochemistry and Molecular Biology, School of Basic Medical Sciences, Southwest Medical University, Luzhou, China

4 Department of Urology, China Medical University/Hospital, Taichung, Taiwan

5 Department of Biostatistics, University of Rochester Medical Center, Rochester, NY, USA 
metastasis in prostate [1, 3, 4, 15-18] and liver [12-14] cancers, yet function as a stimulator to increase metastasis in bladder [7, 8, 19] and kidney [9, 10] cancers. The detailed mechanisms of these differential effects, however, remain unclear.

Circular RNAs (circRNAs), noncoding forms of RNA, are widely expressed in many tissues with distinct functions to influence the development of several diseases including tumor progression [20, 21]. Functions of circRNAs include gene regulation by competing with splicing of linear RNA [22], as templates of rolling circle amplification of RNA, and constraints on RNA folding, as well as acting as intermediates in RNA processing, or as sponges to influence microRNAs (miRNAs) availability in selective cells [23, 24].

The circRNAs are produced as a result of endogenous host gene transcription, and sequence analysis indicated that the AR locus can produce four circRNAs from a combination of exons. The linkage of these AR gene-coded circRNAs to the differential effects on the cell invasion of prostate cancer $(\mathrm{PCa})$ vs. bladder cancer $(\mathrm{BCa})$ in response to androgen-deprivation therapy (ADT) with the antiandrogen Enzalutamide (Enz) treatment (ADT-Enz), however, remains unclear.

Here we found that targeting androgens/AR with ADTEnz or AR-shRNA led to increase AR-encoded circRNAs expression in PCa cells, yet suppress those circRNAs in $\mathrm{BCa}$ cells. The consequence of such differential alteration of the AR-encoded circRNAs may then increase PCa cell invasion, yet decrease BCa cell invasion. Further mechanistic analysis revealed that Enz/AR/AR-encoded circRNAs signaling might function via sponging/altering the expression of miR-125b-2-3p and/or miR-4736 to influence the metastasis-related PPAR $\gamma /$ MMP-9 signals to impact the $\mathrm{PCa}$ vs. $\mathrm{BCa}$ cell invasion.

\section{Results}

\section{ADT with antiandrogen Enz or AR-shRNA differentially modulates the expression of the AR-encoded circRNAs}

Early studies indicated that AR could enhance BCa metastasis [7, 8] yet suppress PCa metastasis [1, 3, 10, 15, 16]. The detailed mechanisms of why AR can play opposite roles to impact the metastasis of these two urological tumors, however, remain unclear.

Here we first focused on the potential role(s) of AR-encoded circRNAs on the AR's differential alteration of the PCa vs. $\mathrm{BCa}$ cell invasion, as these AR-encoded circRNAs are most closely related to the functional entity of AR. A database (Circbase) search indicated that the AR locus produces four circRNAs (Supplementary Fig. 1A, B). The circRNA-ARC1 was chosen for further study because it had smallest size and its circular property was confirmed by RNase R digestion. Interestingly, results revealed that targeting full-length AR (fAR) with AR-shRNA led to increase the expression of circRNA$\mathrm{ARC1}$ in castration-resistant $\mathrm{PCa}$ (CRPC) $\mathrm{C} 4-2$ and CWR22Rv1 cells (Fig. 1A). In contrast, targeting fAR with AR-shRNA led to an opposite effect of decreasing the expression of circRNA-ARC1 in BCa T24 and TCC-SUP cells (Fig. 1B). These contrasting results suggest that the differential AR function to increase vs. decrease cell invasion in these two urological tumors may involve differential expression of ARencoded circRNA-ARC1.

To further substantiate the linkage between AR protein and AR-encoded circRNAs, we applied the 2nd approach using the recently developed antiandrogen Enz [25] to confirm the above results generated from AR-shRNA. As shown in Fig. 1C, adding Enz to suppress androgen/AR signaling led to increase the expression of circRNAARC1 in CRPC CWR22Rv1 cells, yet decrease the expression of circRNA-ARC1 in BCa T24 and UMUC3 cells (Fig. 1D).

Importantly, we applied the RNase R-digestion assay [26] to confirm the noncoding circRNA-ARC1 is indeed in the circular form as early studies demonstrated that RNase $\mathrm{R}$, a highly processive $3^{\prime}$ to $5^{\prime}$ exoribonuclease, would not digest circRNAs due to a lack of a free $3^{\prime}$ end, yet it could digest linear RNAs with a $3^{\prime}$ single-stranded region of $>7$ nucleotides [27]. As shown in Fig. 1E, F, RNase R did not digest the circRNA-ARC1 while it can potently decrease the level of GAPDH mRNA in both C4-2 and T24 cells, suggesting that circRNA-ARC1 is indeed in the circular form.

Together, results from Fig. 1A-F suggest that targeting fAR with Enz or AR-shRNA can differentially alter the ARencoded circRNA expression in PCa vs. BCa: increasing the circRNA-ARC1 expression in PCa cells, yet decreasing its expression in $\mathrm{BCa}$ cells.

\section{Mechanistic dissection of how targeting the AR can lead to increase circRNA-ARC1 expression in PCa cells, yet decrease its expression in BCa cells}

Since the AR-encoded circRNA-ARC1 is generated from transcription of the endogenous AR locus, we examined the relationship between the AR gene and circRNA-ARC1 expression, with $A R-5^{\prime} \mathrm{UTR}$ as a gauge of endogenous AR transcription. As shown in Fig. 2A, decreasing AR via adding lentiviral AR-shRNA increased the $A R-5^{\prime} \mathrm{UTR}$ in PCa CWR22Rv1 and C4-2 cells. In contrast, increasing AR via adding lentiviral AR-cDNA increased the $A R-5^{\prime} \mathrm{UTR}$ in BCa T24 and UMUC3 cells (Fig. 2B), suggesting that AR-encoded circRNA-ARC1 expression is concordant with the endogenous AR transcription in response to manipulating the AR expression. 
A

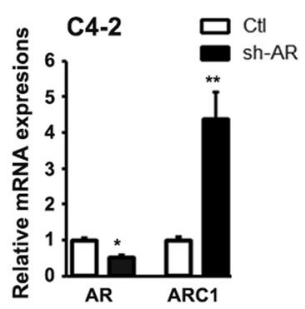

C

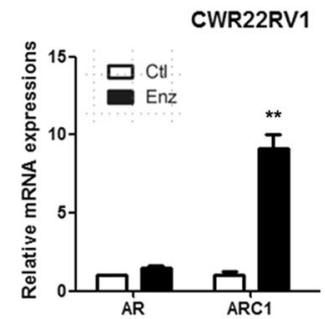

E

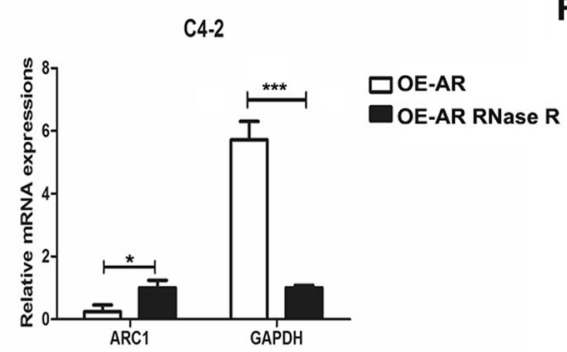

Fig. 1 AR differentially regulates the expression of circRNAs in PCa vs. BCa cell lines. The qPCR analysis of circRNA-ARC1 (ARC1) in response to the knock down of $\mathrm{AR}$ in $\mathrm{C} 4-2$ and CWR22Rv1 cells (A), and in T24 and TCC-SUP cells (B). Effect of Enz treatment on expression of circRNA-ARC1 in PCa and BCa cell

To further determine whether the differential expression of circRNA-ARC1 is linked with endogenous transcription of the $A R$ locus, we applied the CRISPR-dCAS9-mediated transcriptional regulation [28] to examine the linkage of circRNA-ARC1 and its host gene-AR transcription. Results from transcriptional regulation from a combination of multiple sgRNAs targeting the promoter and enhancer of AR suggest that endogenous AR transcription is positively linked with circRNA-ARC1 production in PCa CWR22Rv1 and C4-2 as well as BCa TCC-SUP cells (Fig. 2C).

Together, results from Fig. 2A-C demonstrate that the differential alterations of the circRNA-ARC1 via targeting the AR are a result of differentially altering the endogenous AR transcription in PCa vs. BCa cells.

To further dissect the molecular mechanisms underlying the differential regulation of $\mathrm{AR}$ transcription in response to altering the AR, we focused on the AR binding to the two androgen-response elements (AREs), one (ARE1) located on the 1-kb upstream of AR gene and another (ARE2) located in the intron 3 [29]. We were interested to see if the

\section{B}
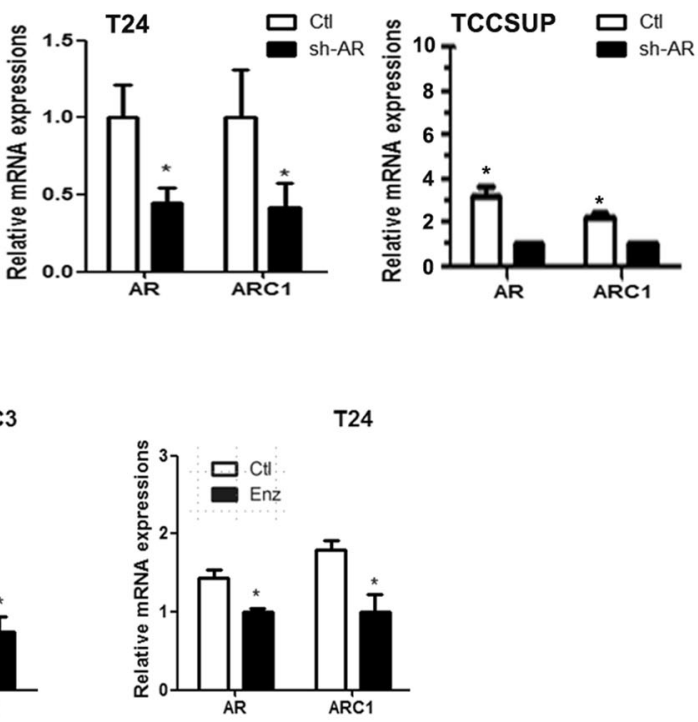

T24

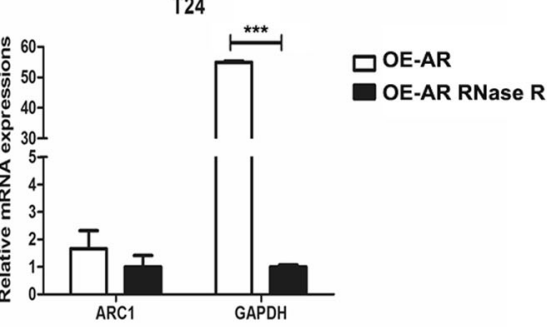

lines. The qPCR analysis of ARC1 expression after Enz treatment in CWR22Rv1 cell line (C) and in UMUC3 and T24 cells (D). RNase R-digestion assay to confirm circularity of ARC1 in C4-2 cells (E) and T24 cells $(\mathbf{F})$. Data are presented as mean \pm SEM. $* P<0.05$, $* * P<0.01, * * * P<0.001$.

autoregulation of AR may be different between $\mathrm{PCa}$ and $\mathrm{BCa}$ cells due to the differential binding of AR to the different AREs, so that circRNA-ARC1 was differentially expressed upon targeting the AR with Enz or shAR treatment. As shown in the Fig. 2D, a strong binding of AR to ARE1 was observed in the BCa UMUC3 cells, which could be released upon Enz treatment. However, instead of binding to ARE1, we found AR preferentially bound to ARE2 in the PCa C4-2 cells and this binding was diminished in the presence of Enz (Fig. 2E). Using histone $\mathrm{H} 3$ lysine4 methylation as an indicator of transcription activation to further dissect the mechanism, we found that $\mathrm{H} 3 \mathrm{~K} 4 \mathrm{me} 2$ was highly enriched around ARE2, but not ARE1 in PCa C4-2 cells, and this enrichment was much more obvious upon Enz treatment, indicating a negative autoregulation of AR transcription in the PCa cells (Fig. 2E). In contrast, $\mathrm{H} 3 \mathrm{~K} 4 \mathrm{me} 2$ enrichment was clearly observed around ARE1, but not ARE2, in the BCa UMUC cells, and this enrichment could be reduced in the presence of Enz, suggesting a positive autoregulation of AR transcription in BCa cells (Fig. 2D). 
Fig. 2 AR may influence PCa vs. BCa cell invasion via altering the circRNA-ARC1.

A Endogenous transcripts of AR and circRNA-ARC1 (ARC1) as measured by primers for fulllength $\mathrm{AR}$ and $\mathrm{AR}-5^{\prime} \mathrm{UTR}$ through semi-quantitative PCR assays in CWR22Rv1 and C4-2 cells in response to knocking down AR (shAR). B As in A qPCR assays in T24 and TCCSUP cells with overexpressed AR (OEAR). C CRISPRdCAS9-mediated transcriptional repression results in repression of $\mathrm{ARC} 1$ expression in $\mathrm{PCa}$ CWR22Rv1 and BCa TCC-SUP cells. (D-E) ChIP assay with AR antibody or H3K4me2 antibody of the two AREs in UMUC3 (D) and C4-2 (E) cells with and without Enz treatment. IgG served as negative control.

F Knocking down ARC1 (shARC1)-suppressed cell invasion induced by knocking down AR (shAR) in

CWR22RV1 and C4-2 cells.

Invasion assay was performed in cells infected with the indicated lentiviral constructs.

Representative microscopic photographs of invaded cells (original magnification, $\times 100$ ) are shown in left panels. G Knocking down ARC1 (shARC1)-suppressed cell invasion induced by overexpression of AR (OEAR) in BCa T24 (upper panels) and TCC-SUP (lower panels) cells. Invasion assay was performed in cells that had been delivered with the indicated lentiviral constructs. Representative microscopic photographs of invaded cells (original magnification, $\times 100$ ) were shown. H Overexpression of $\mathrm{ARC} 1$ can rescue cell invasion in PCa cells repressed by overexpression of AR in CWR22Rv1 (upper panels) cells and knocking down $\mathrm{AR}$ in $\mathrm{BCa}$ TCC-SUP (lower panels) cells. For $\mathbf{F}-\mathbf{H}$, the right panels indicate the quantitation of the cell invasion in the left panels. Scale bar: $20 \mu \mathrm{m}$. Data are presented as mean \pm SEM. $* P<$ $0.05, * * P<0.01, * * * P<0.001$.
A
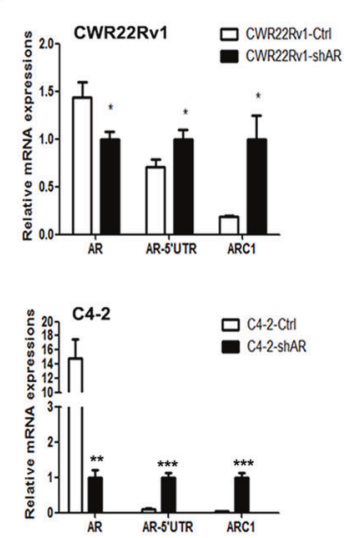

D

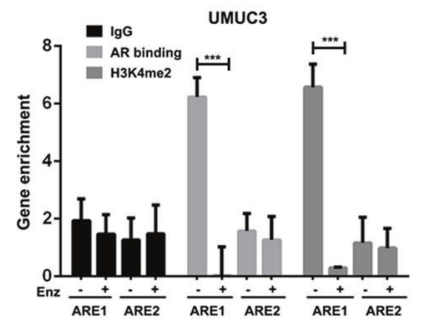

B
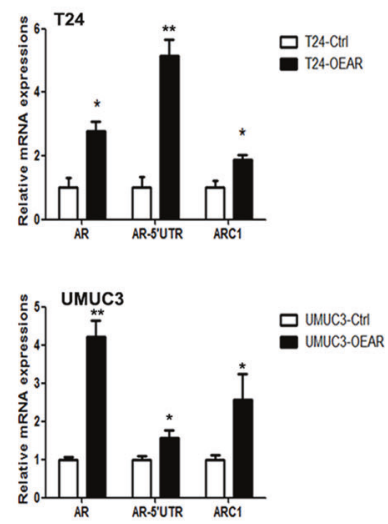

E
C
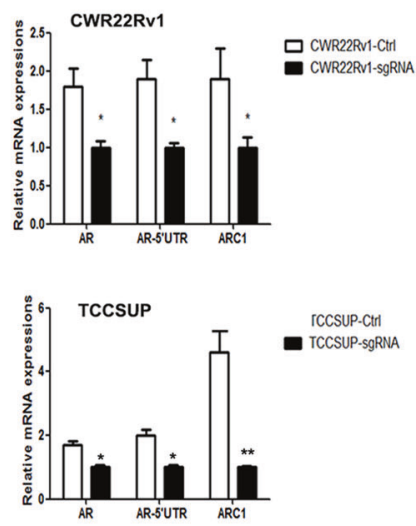

F

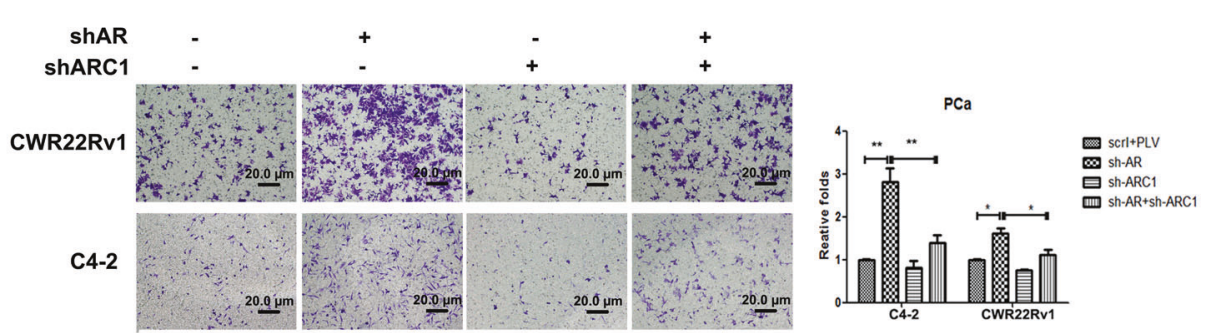

G
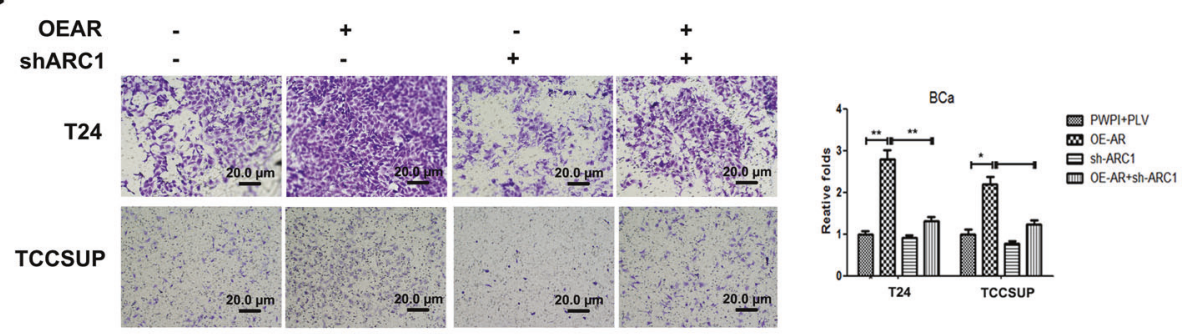

H
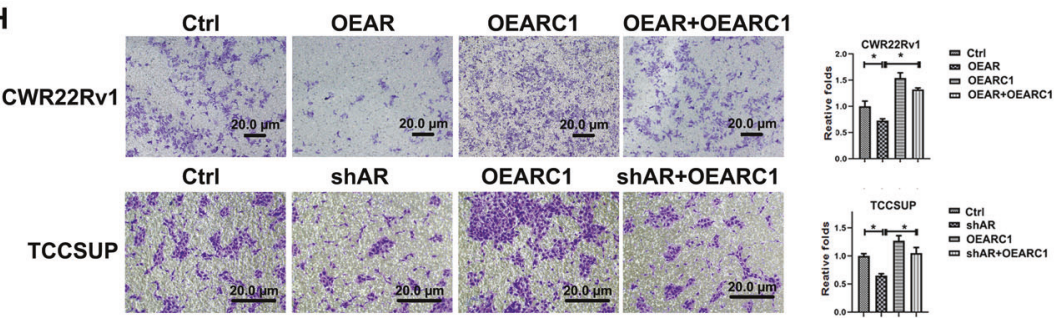
Together, results from Fig. 2A-E suggest that AR may play a positive autoregulation role in $\mathrm{BCa}$ via binding to ARE1 while a negative autoregulation role in $\mathrm{PCa}$ via binding to ARE2, and these opposing autoregulation roles may then result in increasing the circRNA-ARC1 expression in $\mathrm{PCa}$ cells, yet decreasing its expression in $\mathrm{BCa}$ cells.

\section{Differential expression of the circRNA-ARC1 led to AR's differential impact on invasion in PCa vs. BCa cells}

To study the consequences of differentially regulating the circRNA-ARC1 expression induced by targeting androgen/ $\mathrm{AR}$ in the $\mathrm{PCa}$ vs. $\mathrm{BCa}$, we applied the matrigel-coated transwell invasion assay, and results revealed that decreasing fAR (shAR) led to increase cell invasion in both PCa C4-2 and CWR22Rv1 cells (Fig. 2F), yet increasing fAR (OEAR) led to increase cell invasion in both $\mathrm{BCa}$ T24 and TCC-SUP cells (Fig. 2G).

Importantly, interruption approaches via adding shRNA to suppress the circRNA-ARC1 led to partially reverse the AR-shRNA-increased cell invasion in $\mathrm{PCa} \mathrm{C} 4-2$ and CWR22Rv1 cells (Fig. 2F), while partially reversed the AR-increased cell invasion in BCa T24 and TCC-SUP cells (Fig. 2G). Furthermore, adding circRNA-ARC1 partially reversed the AR-decreased cell invasion in PCa CWR22Rv1 cells as well as reversed the AR-shRNA-decreased cell invasion in BCa TCC-SUP cells (Fig. 2H).

Together, results from Fig. 2F-H demonstrate that AR may decrease PCa cell invasion yet increase BCa cell invasion via altering the expression of AR-coded circRNA-ARC1.

\section{Mechanistic dissection of how circRNA-ARC1 can influence the PCa vs. BCa cell invasion: via sponging/altering the miR-125b and/or miR-4736}

Next, to dissect the mechanism of how AR-modulated circRNA-ARC1 can influence the PCa vs. BCa cell invasion, we focused on miRNAs, since early studies indicated that circRNAs might function as a miRNAs sponge or miRNAs reservoir to alter the breast or colorectal tumor progression [30].

Through bioinformatics analysis of existing databases (DIANA miRGen, MicroCosm Targets, RNA22, and RegRNA2.0) and published literatures, we found that circRNA-ARC1 might be able to interact with several miRNAs (see Supplementary Fig. 2A, B). Among these potential candidate miRNAs, we decided to focus on miR-125b-2-3p and miR-4736 since recent studies indicated that these two miRNAs might play key roles to alter the progression of $\mathrm{BCa}$ [31], PCa [32, 33], and spinal chordoma [34].

Indeed, we found that Enz treatment increased PCa cell invasion was reversed/blocked after adding miR-125b-2-3p or miR-4736 in PCa C4-2 cells (Fig. 3A). In contrast, we found that adding miR-125b-2-3p or miR-4736 to $\mathrm{BCa}$ UMUC3 and TCC-5637 cells reversed/blocked the ARincreased BCa cell invasion (Fig. 3B, C). The choice of these two miRNAs was also supported by the failure of miRNA-323a-5p and $-4725-5 p$ to block Enz's effect.

Together, results from Fig. 3A-C suggest that miR-125b2-3p and miR-4736 may play key roles to mediate the circRNA-ARC1-modulated PCa vs. BCa cell invasion.

To examine the molecular basis of the functional interaction between miRNAs and circRNA-ARC1, we applied the pulldown assay to isolate the circRNA-ARC1 via the biotin-labeled oligonucleotide that is complimentary to the fusion junction of the circRNA-ARC1 and measured its associated miRNAs. The results revealed that circRNA-ARC1 could function as a sponge to absorb/interact with miR-125b-2-3p and miR-4736 in both PCa CWR22Rv1 cells and BCa TCC-SUP cells (Fig. 3D).

Importantly, results from the rescue assay revealed that adding miR-125b-2-3p led to partially reverse/block the circRNA-ARC1-increased cell invasion in $\mathrm{PCa} \mathrm{C} 4-2$ and BCa UMUC3 cells (Fig. 3E), yet adding miR-125b-2-3p inhibitor partially reversed/blocked the circRNA-ARC1shRNA-suppressed cell invasion in PCa CWR22Rv1 and BCa T24 cells (Fig. 3F).

Together, results from Fig. 3A-F suggest that ARmodulated circRNA-ARC1 may alter the PCa vs. BCa cell invasion via sponging/interacting with/altering the miR$125 \mathrm{~b}-2-3 \mathrm{p}$ and miR-4736 to further influence the target genes related to tumor cell invasion.

\section{Mechanistic dissection of how circRNA-ARC1/miR- 125b-2-3p/miR-4736 signaling can alter the PCa vs. BCa cell invasion: via modulating the PPARy/ MMP-9 signals}

To further dissect the molecular mechanisms of how ARmodulated circRNA-ARC1/miR-125b-2-3p/miR-4736 signaling can alter the PCa vs. BCa cell invasion, we surveyed those genes related to $\mathrm{PCa}$ vs. BCa metastasis $[35,36]$ and their potential linkages to these miRNAs. Such analyses led us to focus on the PPAR $/$ /MMP-9 signals, as their downstream targets (PPARGC1B and PDK1) are linked to our identified miRNAs [37-40].

To test the role of PPAR $\gamma /$ MMP-9 signals in this process, we first treated cells with the PPAR $\gamma$ antagonist for the transwell invasion assay, and results revealed that AR-altered cell invasion was particularly sensitive to the PPAR $\gamma$-antagonist III in BCa UMUC3 cells and PCa C4-2 cells (Fig. 4A1, A2). Consistent with these results, adding PPAR $\gamma$-antagonist III also partially reversed AR-increased MMP-9 expression in $\mathrm{BCa}$ UMUC3 and PCa C4-2 cells (Fig. 4A3).

Together, results from Fig. 4A1-A3 suggest that AR may function via altering the PPAR $\gamma / \mathrm{MMP}-9$ signals to modulate the PCa vs. BCa cell invasion. 
A
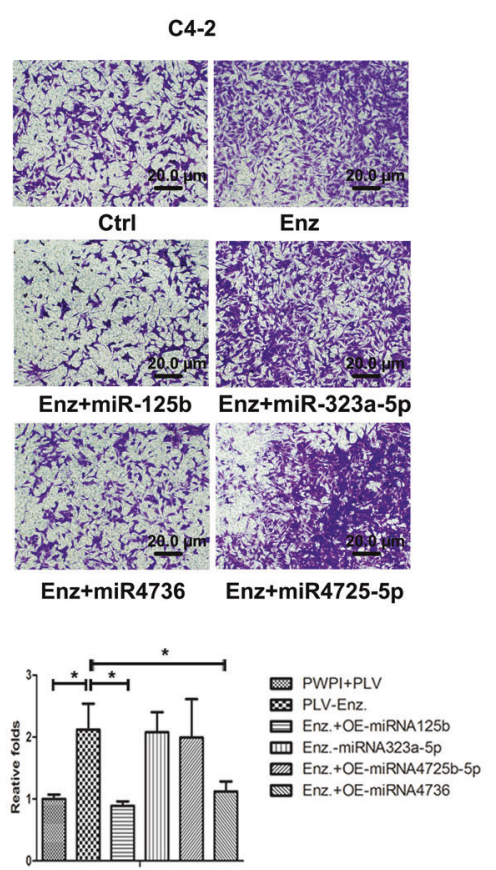

B
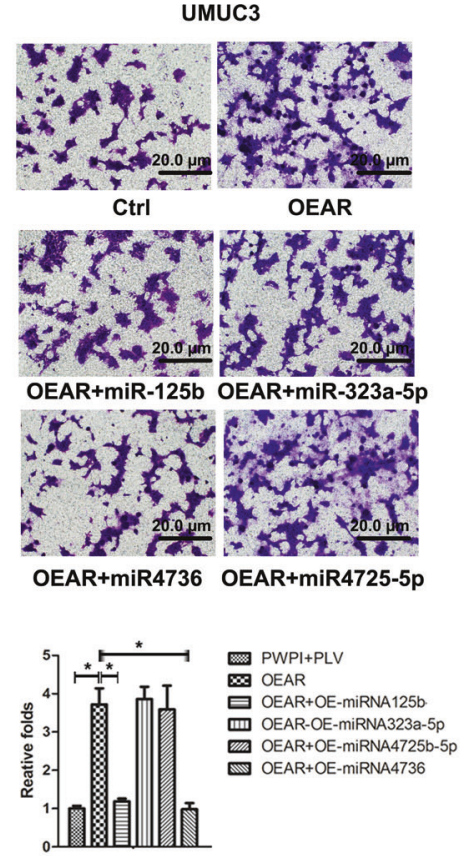

C
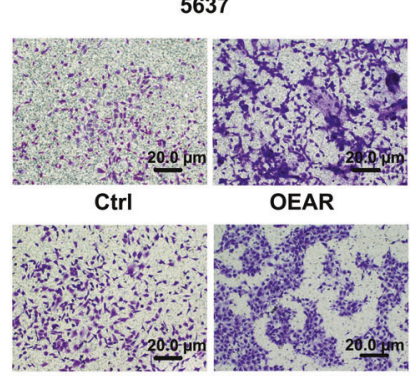

OEAR+miR-125b OEAR+miR-323a-5p
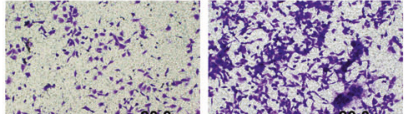

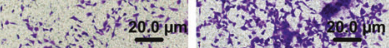

OEAR+miR4736 OEAR+miR4725-5p

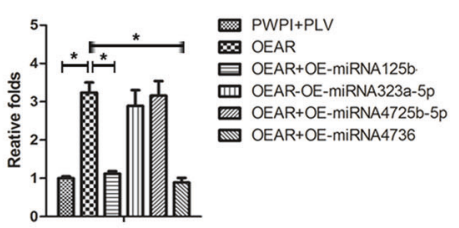

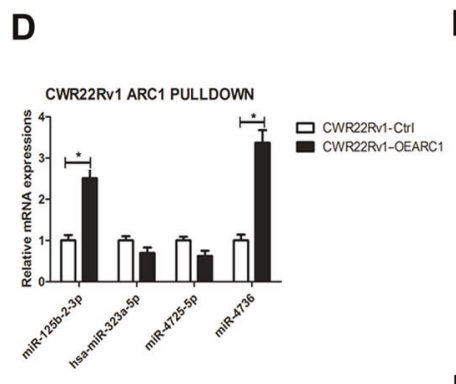

E

$\mathbf{F}$
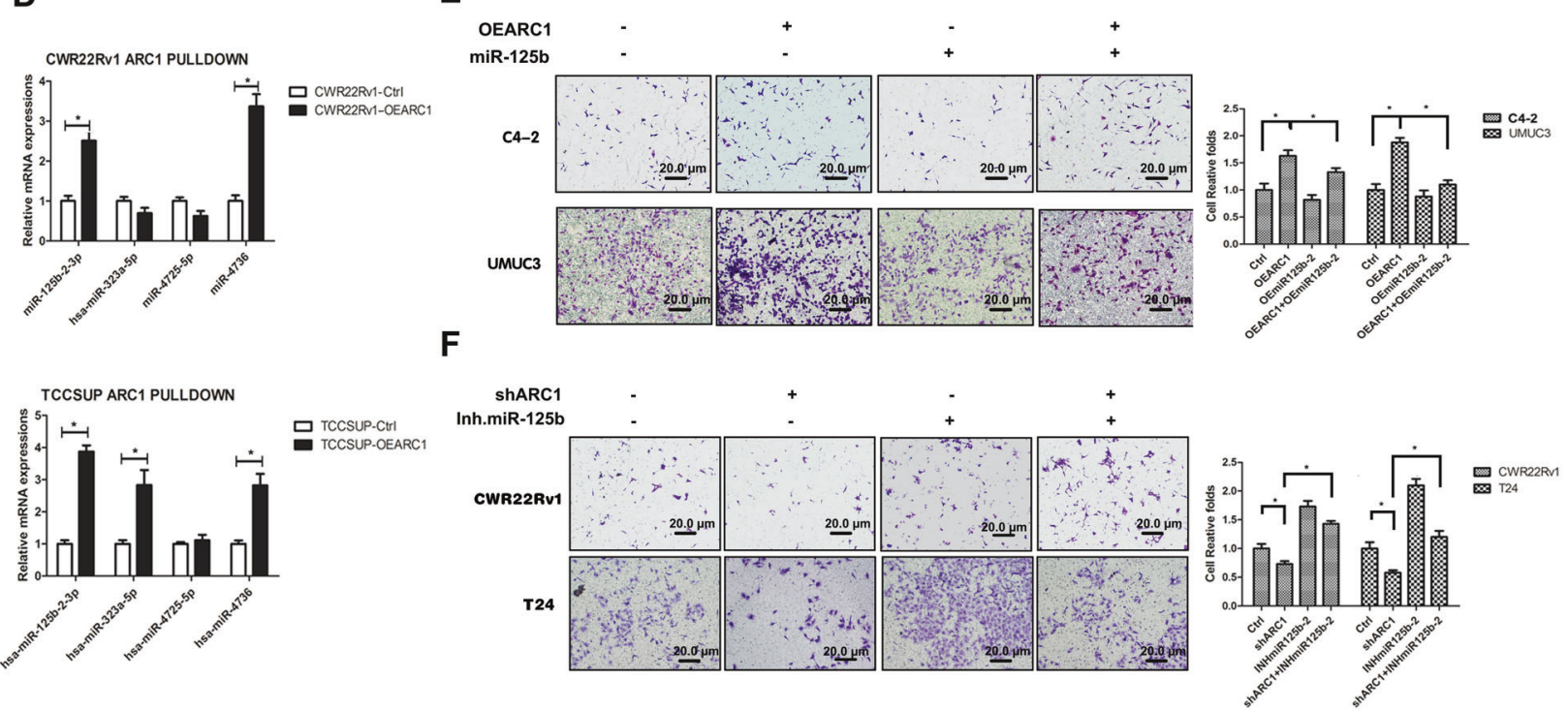

Fig. 3 AR-circRNA-ARC1 regulates $\mathrm{PCa}$ vs. $\mathrm{BCa}$ cell invasion through miR-125b-2-3p and/or miR-4736. A The miRNAs can repress cell invasion induced by Enz in PCa C4-2 cells. Invasion assay was performed in C4-2 cells transduced with the indicated lentiviral constructs with Enz treatment $(10 \mu \mathrm{M}, 48 \mathrm{~h})$. The miRNAs can repress cell invasion induced by overexpression of AR in BCa UMUC3 (B) and TCC-5637 (C) cells. Invasion assays were performed in BCa cells transduced with the indicated lentiviral constructs. For A-C top panels, representative microscopic photographs of invaded cells (original magnification, $\times 100$ ) were shown, with lower panels quantitation of images (cell numbers were counted in six randomly chosen microscopic fields per membrane). Scale bar: $20 \mu \mathrm{m}$. D The circRNAARC1 (ARC1) can interact with miRNA-125b-2-3p and miR-4736 in
PCa and BCa cells. ARC1 was pulled-down on the streptavidin beads by biotinylated oligonucleotide complimentary to the fusion junction of the circRNA-ARC1. The miRNAs associated with the ARC1 were determined through quantitative PCR of the respective miRNAs in PCa CWR22Rv1 and BCa TCC-SUP cells with or without overexpression of ARC1. E miR-125b-2-3p can suppress ARC1-induced cell invasion in PCa C4-2 (upper panels) and BCa UMUC3 (lower panels) cells. F miRNA-125b-2-3p inhibitor can rescue cell invasion repressed by ARC1-knocked down in PCa CWR22Rv1 (upper panels) and BCa T24 (lower panels) cells. For E, F left panels are representative microscopic photographs of invaded cells and right panels the quantitation of cell invasion. Scale bar: $20 \mu \mathrm{m}$. Data are presented as mean \pm SEM. $* P<0.05$. 
A $\quad$ A1

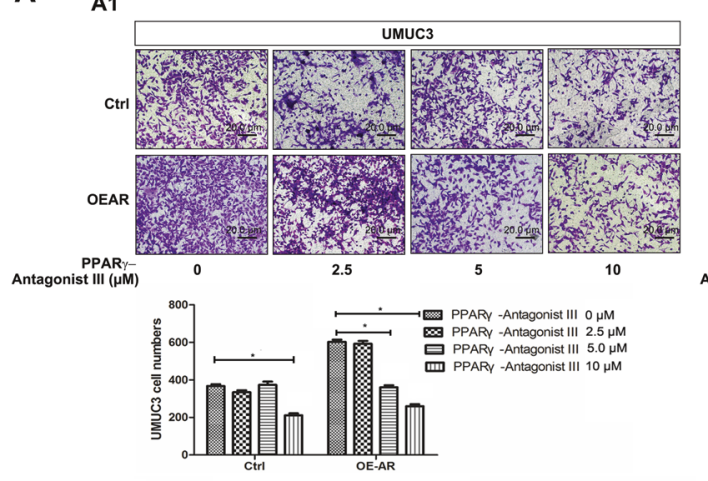

A3

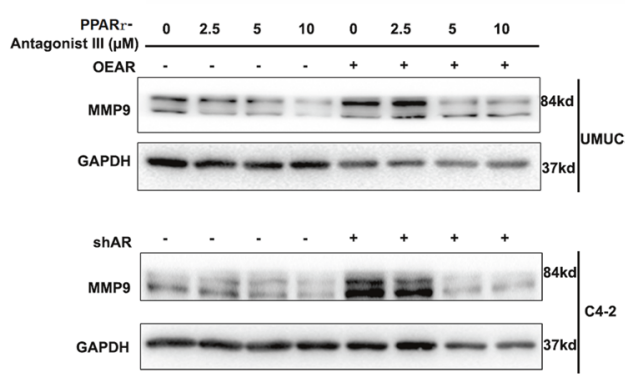

B
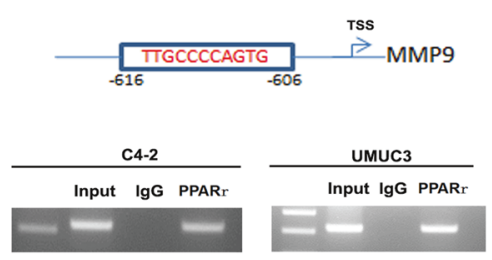

D

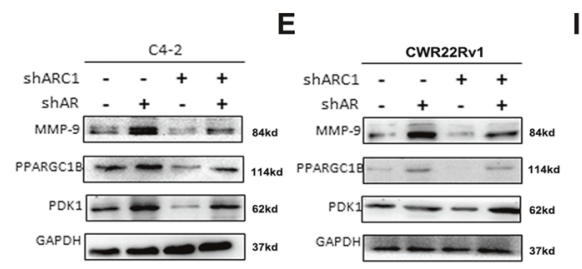

$\mathbf{F}$

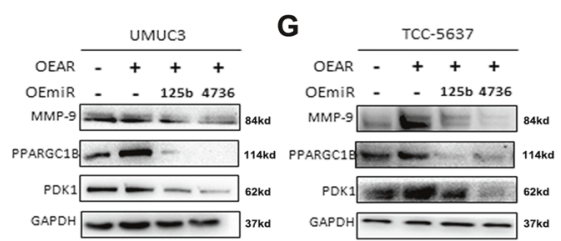

H

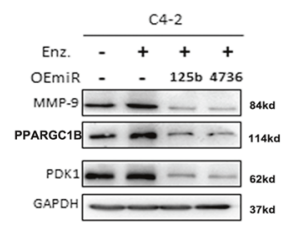

To further dissect the mechanism of how PPAR $\gamma$ can modulate the MMP-9 at the molecular level, we identified one potential PPAR $\gamma$-response element (PPAR $\gamma \mathrm{RE})$ via

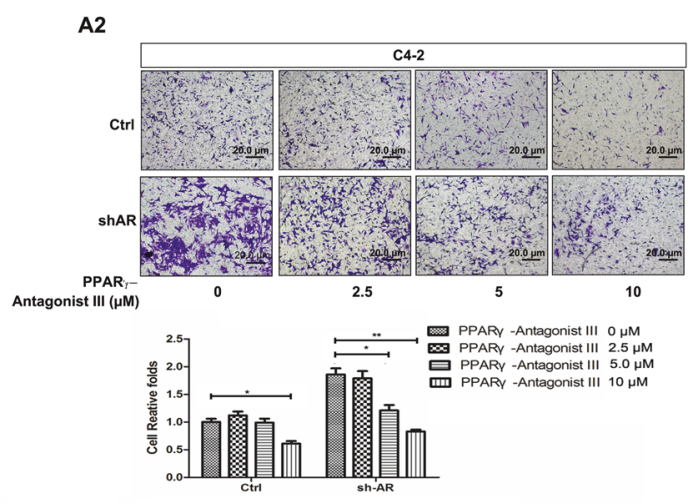

C
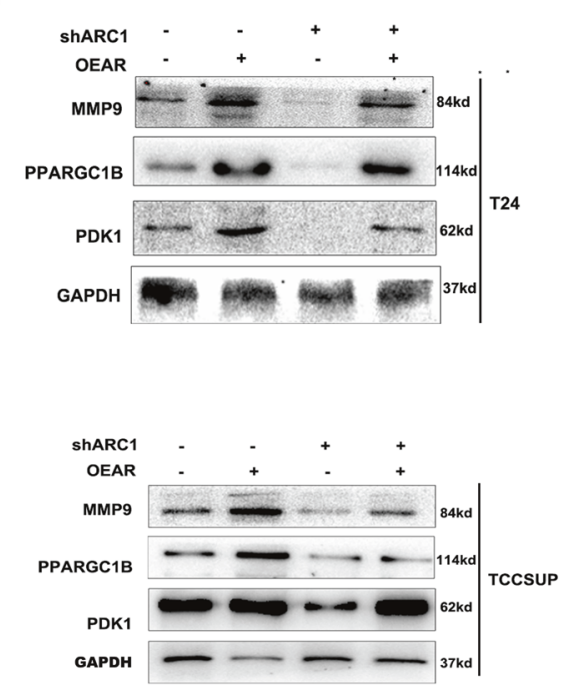

J
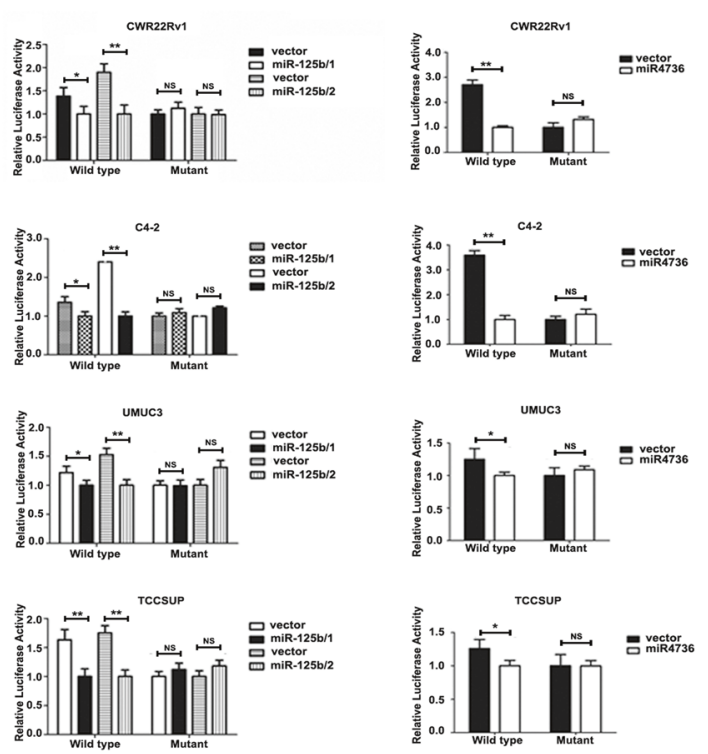

PROMO website in the $1-\mathrm{kb} 5^{\prime}$ promoter region of the MMP-9 gene (Fig. 4B). We then used the chromatin immunoprecipitation (ChIP) in vivo binding assay to detect 
Fig. 4 AR-modulated circRNA-ARC1/miR-125b-2-3p/miR-4736 signals regulated $\mathrm{PCa}$ vs. $\mathrm{BCa}$ cell invasion via altering the PPARGC1B/PDK1/MMP-9 signals. Treating with PPAR $\gamma$ antagonist III can suppress cell invasion induced by overexpression of $\mathrm{AR}$ in $\mathrm{BCa}$ UMUC3 cells (A1) and knocking down AR in PCa C4-2 cells (A2). Invasion assays were performed in cells that had been delivered with the indicated lentiviral constructs and treated with different concentrations of the antagonist. Top panels, representative microscopic photographs of invaded cells (original magnification, $\times 100$ ) were shown. Bottom panels, the quantitation of cell invasion in A1, A2. Scale bar: $20 \mu \mathrm{m}$. A3 MMP-9 expression was regulated by AR expression and PPAR $\gamma$ antagonist in BCa UMUC3 (upper panels) and PCa C4-2 (lower panels) cells. B MMP-9 promoter analysis using online software ALGGEN PROMO. The top panel indicates that there is a PPAR $\gamma$ binding element (PPAR $\gamma R E$ ) upstream of MMP-9 transcription start site (TSS). The lower panel indicates the results of chromatin immunoprecipitation (ChIP) results in $\mathrm{PCa}$ C4-2 (left) and $\mathrm{BCa}$ UMUC3 (right) cells. C Knocking down circRNA-ARC1 (ARC1) can suppress expression of MMP-9, PPARGC1B, and PDK1 induced by overexpression of AR in BCa T24 (upper panels) and TCC-SUP (lower panels) cells. Knocking down ARC1 can suppress expression of MMP-9, PPARGC1B, and PDK1 induced by knocking down AR in PCa C4-2 (D) and CWR22Rv1 (E) cells. The miR-125b-2-3p and miR-4736 can suppress expression of MMP-9, PPARGC1B, and PDK1 induced by overexpression of AR in BCa UMUC3 (F) and TCC-5637 (G) cells. H The miR-125b-2-3p and miR-4736 can suppress expression of MMP-9, PPARGC1B, and PDK1 induced by Enz in PCa C4-2 cells. I, J The miRNA-125b-2-3p modulates reporter activity of $3^{\prime} \mathrm{UTR}$ of PPARGC1B/PDK1. Normalized luciferase activity was measured after transfection of wild-type or mutant PPARGC1B/PDK1 3'UTR reporter construct in cells transduced with the indicated lentiviral constructs for miR-125b-2-3p or miR-4736 in $\mathrm{PCa}(\mathbf{I})$ and $\mathrm{BCa}(\mathbf{J})$ cells. Data are presented as mean \pm SEM. $* P<0.05$, $* * P<0.01$, and $\mathrm{NS}=$ no significant difference.

PPAR $\gamma$ binding to this potential PPAR $\gamma \mathrm{RE}$, and revealed that PPAR $\gamma$ could bind to the PPAR $\gamma$ RE located in the $5^{\prime}$ promoter region of MMP-9 (Fig. 4B), suggesting that PPAR $\gamma$ may directly regulate MMP-9 expression via regulating PPAR $\gamma$ binding to the PPAR $\gamma$ RE.

Consistent with the direct regulation of the MMP-9 by PPAR $\gamma$, we also confirmed that increasing AR via adding ARcDNA in both BCa T24 and TCC-SUP cells significantly increased the expression of MMP-9 (Fig. 4C). In contrast, decreasing AR via adding AR-shRNA increased the expression of MMP-9 in PCa C4-2 and CWR22Rv1 cells (Fig. 4D, E). Importantly, AR-induced MMP-9 in BCa cells or shARincreased MMP-9 in PCa cells could be partially blocked by the altering circRNA-ARC1 expression (Fig. 4C-E).

Together, results from Fig. 4B-E suggest that PPAR $\gamma$ may transcriptionally regulate the MMP-9 expression via direct binding to the PPAR $\gamma R E$ on its $5^{\prime}$ promoter region.

To further demonstrate that AR-modulated circRNAARC1 may function via sponging/altering the miR-125b-23p/miR-4736 to regulate PPAR $\gamma /$ MMP-9 signals, we applied the interruption approach, and results revealed adding miR-125b-2-3p or miR-4736 led to reverse the ARenhanced expression of PPARGC1B and PDK1 as well as MMP-9 in BCa cells (Fig. 4F, G). Similar results were also obtained showing that exogenous miR-125b-2-3p/miR4736 in PCa C4-2 cells led to reverse the Enz-increased PPARGC1B/PDK1-MMP-9 expression (Fig. 4H).

It is worth noting that adding either miR-125b-2-3p or miR4736 can result in repression of both PDK1 and PPARGC1B expression to a different degree in both $\mathrm{PCa}$ and $\mathrm{BCa}$ cells. Indeed, a survey of potential miRNA target genes with a relaxed criterion in target selection in the database of Targetscan indicated that both miRNAs can target both genes albeit with different predictive stringencies.

Interestingly, human clinical sample surveys using TCGA datasets revealed that $\mathrm{AR}$ has a positive correlation with PPAR $\gamma$, PDK1, and PPARGC1B (Supplementary Fig. 3A-C).

Together, results from Fig. 4A-H suggest that Enz/AR may differentially impact the $\mathrm{PCa}$ vs. $\mathrm{BCa}$ cell invasion via altering the AR-modulated circRNA-ARC1/miR-125b-23p/miR-4736/PPAR $\gamma /$ MMP-9 signals.

\section{Mechanistic dissection of how AR/circRNA-ARC1/ miR-125b-2-3p/miR-4736 axis can alter the PPARGC1B/PDK1 expression: via direct binding to its 3'UTR mRNA}

To dissect the molecular mechanism of how miR-125b-2-3p can modulate the PPARGC1B expression, we first identified two potential miRNA target sequence in the $3^{\prime} \mathrm{UTR}$ mRNA of PPARGC1B. We then inserted 915 and 1196-bp fragments from the PPARGC1B 3'UTR mRNA with the predicted miR$125 b-2-3 p$ target site into a dual-luciferase reporter psiCHECK $^{\mathrm{TM}}$-2 downstream of the Renilla luciferase ORF, as well as prepared a mutated version at the predicted target site.

As expected, the Luciferase Assay results revealed that expression of miR-125-2-3p markedly decreased luciferase activity in PCa CWR22Rv1 or C4-2 cells as well as BCa UMUC3 or TCC-SUP cells transfected with the wild-type PPARGC1B 3'UTR, but not the mutant PPARGC1B $3^{\prime}$ UTR (Fig. 4I).

Similar results were also obtained when we replaced miR125-2-3p with miR-4736 binding to the wild-type PDK1 $3^{\prime}$ UTR via insertion of the 972-bp fragment from the PDK1 $3^{\prime}$ UTR with the predicted miR-4736 target site into the psiCHECK $^{\mathrm{TM}}-2$ vector as well as a mutated version at the predicted target site in the same PCa and BCa cells (Fig. 4J).

Together, results from Fig. 4I, J suggest that miR-125b2-3p/miR-4736 can directly regulate PPARGC1B/PDK1 expression via direct binding to their $3^{\prime}$ UTRs mRNA.

\section{Preclinical study using the in vivo mouse model to prove circRNA-ARC1 roles in the Enz-induced PCa metastasis}

To validate the above results from in vitro studies of $\mathrm{PCa}$ and $\mathrm{BCa}$ cell lines in vivo, we applied an orthotopic $\mathrm{PCa}$ 
xenograft mouse model. We generated CWR22Rv1 cells with luciferase expression with added sh-circRNA-ARC1 (Groups 3 and 4) to suppress circRNA-ARC1 expression or with vector control (Groups 1 and 2) and implanted these cells into the anterior prostate lobes of nude mice $(n=32$ for each group), with (Groups 2 and 4) or without (Groups 1 and 3) intra-peritoneal (i.p) injection of Enz $(30 \mathrm{mg} / \mathrm{kg})$. Tumor growth and metastases were evaluated weekly with the In Vivo Imaging Systems (IVIS) analysis in a noninvasive manner.

After 6 weeks, IVIS imaging showed that treating with Enz led to increase the PCa metastasis (Fig. 5A, Group 2 vs. Group 1). Importantly, Enz failed to promote PCa metastasis when circRNA-ARC1 expression was suppressed with sh-circARC1 (Fig. 5A, Group 3 vs. Group 4). Similar results were also obtained showing that suppressing circARC1 expression led to decrease the metastatic luciferase signals upon Enz treatment (Fig. 5A, Group 4 vs. Group 2). We also confirmed the IVIS assays with direct measurement of the metastatic tumor growth with the $\mathrm{H} \& \mathrm{E}$ staining in pelvic lymph nodes and the diaphragm (Fig. 5B, C).

Importantly, our IHC staining from these PCa xenografts demonstrated that suppressing circARC1 led to decrease the MMP-9 expression compared to that from the control group, consistent with our in vitro findings. We also found that there was no significant difference of AR expression among different groups (Fig. 5D).

Together, results from in vivo mouse model studies in Fig. 5A-D are in agreement with the in vitro cell lines studies and demonstrated that targeting the circRNA-ARC1 could suppress the Enz-increased PCa metastasis via altering the circRNA-ARC1/miR-125b-2-3p/miR-4736/PPAR $\gamma /$ MMP-9 signals (see outline in Fig. 6).

\section{Discussion}

$\mathrm{PCa}$ is a leading cause of cancer death among males in western countries, and increasingly so in the developing countries like China [41, 42]. BCa ranks the highest among urinary tumors in the world with a clear male dominance in incidence [43]. Recent studies also indicated that AR might play positive roles to promote tumor cell proliferation in both $\mathrm{PCa}$ and $\mathrm{BCa}$ cells [44]. However, as shown in this study, AR may also play opposite roles to increase BCa cell invasion, yet suppress PCa cell invasion.

The circRNAs are the non-encoding RNAs that are mainly located on the exons, but can also occur in any genomic region, with $85 \%$ of circRNAs aligned in sense orientation to known protein-coding genes that can span 1-5 exons [24, 45]. The circRNAs are likely more stable than linear RNAs as a result of inherent higher resistance to nuclease activity. In addition, circRNAs can also function as a natural sponge of miRNAs [46-48] to link their importance in the disease regulation [24, 29,30], including anticancer effects in malignant melanoma tumors [49].

Our findings here that ADT-Enz (or AR-shRNAs) may function via differentially altering the AR-encoded circRNA-ARC1 to increase PCa metastasis, yet decrease $\mathrm{BCa}$ metastasis, not only may help treatment to improve the ADT-Enz therapy efficacy via reducing those adverse effects, it may also represent the first evidence to link ARencoded circRNAs to the differential anti-AR therapies. Interestingly, a recent study also found that AR might suppress its transcription in a LSD1-dependent manner [50], and ADT-Enz therapy may de-repress the AR transcription, which can then result in increasing the AR transcription to produce more AR protein to function in the castration environment with lower androgen levels [51]. Here we found that, in addition to AR protein encoded by the $A R$ locus, the $A R$ transcription could also result in generating additional molecules, like circRNAs, to play roles via sponging the miRNAs to regulate cell invasion and likely tumor metastasis. It will be interesting in the future studies to see if ADT-Enz may also function via differentially regulating AR-encoded circRNAs to further impact those ADT-Enz-induced adverse effects that involve altering either GR signals [52], AR-coactivator NCOA2 signals [3], or TGFß1 signals [53].

The precise mechanisms at the molecular level of how differential complexes may guide AR to bind to the distinct AREs located on different regions of the AR gene remain unclear. Our data showed that AR preferred to bind to the ARE1 in BCa cells, yet preferred to bind to the ARE2 in PCa cells. These differential bindings of AR to the different AR loci resulted in a positive autoregulation in BCa cells vs. a negative autoregulation in PCa cells, which was monitored by $\mathrm{H} 3 \mathrm{~K} 4 \mathrm{me} 2$ levels. It is likely the tumor origin of tissues as well as cellular signaling networks in the PCa vs. $\mathrm{BCa}$ are different so that $\mathrm{AR}$ may associate with different co-factors/co-repressors to form distinct complexes that result in binding to different AREs in the AR locus, and consequences of such differential binding may then result in a positive autoregulation in $\mathrm{BCa}$ cells vs. a negative autoregulation in $\mathrm{PCa}$ cells. Indeed the expression of $\mathrm{AR}$ protein in PCa vs. BCa cells is also different with much higher AR protein detected in the PCa cells.

The human clinical data indicated that ADT is an effective therapy in suppressing the recurrence of AR-positive BCa cells [54], with its therapeutic durability in BCa up to 2-3 years. In $\mathrm{PCa}$, results from a recent NGS effort in a large cohort of $\mathrm{PCa}$ samples suggested that constitutively active AR splice variants may be linked to the cell invasion in $40-50 \%$ of CRPC patients [55]. It will be interesting in the future to see if targeting this newly identified AR/circRNA-ARC1/miR-125b-23p/miR-4736/PPAR $\gamma /$ MMP-9 signaling with small molecules 
A

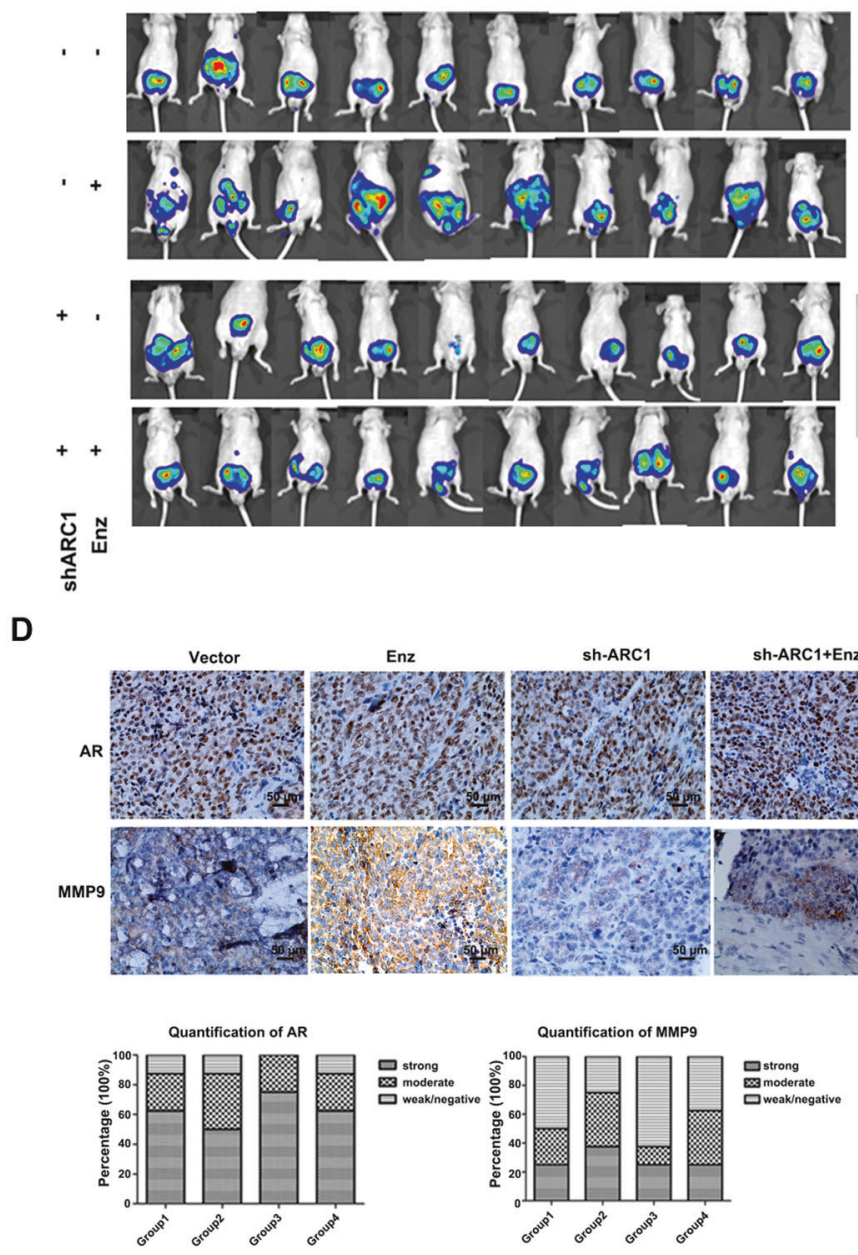

B

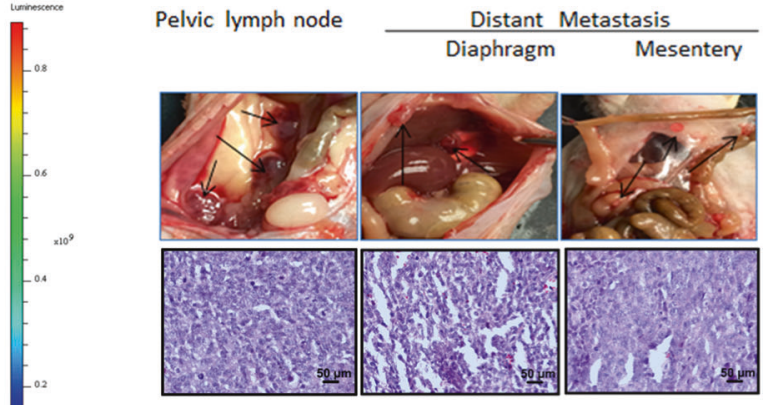

C

\begin{tabular}{|c|l|l|l|}
\hline & $\begin{array}{l}\text { Pelvic } \\
\text { Lymph } \\
\text { Node }\end{array}$ & Diaphragn & mesenteric \\
\hline $\begin{array}{c}\text { Group1 } \\
\text { CWR22RV1 Vector }\end{array}$ & 5 & 3 & 2 \\
\hline $\begin{array}{c}\text { Group2 } \\
\text { CWR22RV1 Enz. }\end{array}$ & 10 & 5 & 8 \\
\hline $\begin{array}{c}\text { Group3 } \\
\text { CWR22RV1 sh-ARC1 }\end{array}$ & 5 & 1 & 1 \\
\hline $\begin{array}{c}\text { Group4 } \\
\text { CWR22RV1 Enz.+sh-ARC1 }\end{array}$ & 4 & 3 & 5 \\
\hline
\end{tabular}

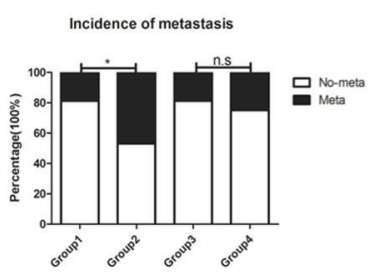

Fig. 5 In vivo mice studies confirmed the role of Enz and ARC1 in PCa metastasis. A IVIS imaging was used to determine the metastasis in each group of mice as indicated. The images were obtained at different times with the same exposure and digitally arranged. B Representative images of pelvic lymph node, diaphragm, mesentery metastasis (upper panesl) with IHC staining in lower panels. C Tabulation of mice with metastasis. Metastatic site tabulations were listed. Chi-square test was used to analyze the results (upper panel), Enz significantly promoted CWR22Rv1 PCa metastasis (15 mice in

(for example, shRNA of circRNA-ARC1 as shown in our in vivo mice data) may help in the development of novel therapeutic approaches to increase the Enz efficacy with less adverse effects to better suppress metastases in patients with $\mathrm{PCa}$ and $\mathrm{BCa}$.

\section{Materials and methods}

\section{Cell culture and transfection}

The human PCa cell lines, C4-2 and CWR22Rv1, the BCa cell lines, T24, TCC-SUP, UMUC3, TCC-5637, and 293T,
Enz treated group $(n=32)$ vs. 6 mice in vehicle-treated group $(n=$ 32), $P=0.015$ ) and Enz failed to promote tumor metastasis when circRNA-ARC1 was knocked down (lower panel). The Pearson's chisquare test shows significant differences among all four groups $(P$ value $=0.0349)$. D H\&E staining confirmed the tumor tissue and representative images of IHC staining for AR and MMP-9 with quantitations (lower panels) on the right as mean \pm SEM. $* P<0.05$ and $\mathrm{ns}=$ no significant difference.

were originally purchased form American Type Culture Collection (ATCC, Manassas, VA). All PCa cells were cultured in RPMI 1640. All BCa cells were cultured in DMEM, all the media contained 10\% FBS, penicillin (25 units $/ \mathrm{ml})$, and streptomycin $(25 \mu \mathrm{g} / \mathrm{ml})$ while cells were cultured in the humidified $5 \% \mathrm{CO}_{2}$ environment at $37^{\circ} \mathrm{C}$.

To generate $\mathrm{AR}$ overexpressing or $\mathrm{AR}$ knocked-down stable cell populations, C4-2, CWR22Rv1, T24, TCC-SUP, UMUC3, or TCC-5637 cells were infected with lentiviral vectors, pWPI-AR/pWPI-Vec or pLKO1-sh-AR/pLKO1scr. The lentiviruses were produced in $293 \mathrm{~T}$ cells with the psAX2 packaging plasmid and pMD2G envelope plasmid together with the transfer plasmid. After $48 \mathrm{~h}$ transfection, 


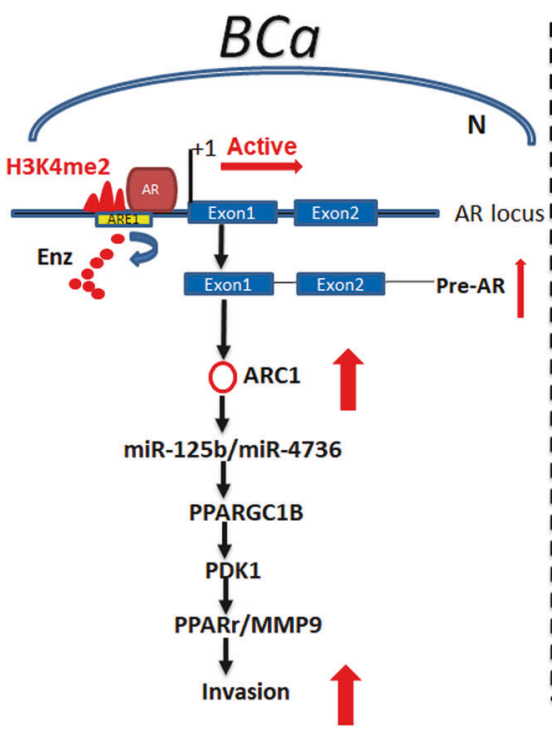

Fig. 6 Schematic depiction that AR and Enz could differentially regulate cell invasion of $\mathrm{BCa}$ and $\mathrm{PCa}$ via differential modulation of the circRNA-ARC1/miRNAs/PPARGC1B/PDK1/MMP-9 signals. In $\mathrm{BCa}$, AR binds ARE1 (located in the $5^{\prime}$ upstream of AR locus) and promotes the generation of pre-AR and ARC1 by activating AR transcription. In PCa, AR prefers to bind ARE2 (located in the intron 2 of $\mathrm{AR}$ locus) and decreases the production of pre-AR and ARC1 by

virus supernatants were collected, concentrated, and frozen at $-80{ }^{\circ} \mathrm{C}$ for later use. Enz and PPAR $\gamma$-Antagonist III treatments were performed by culturing cells with $10 \mu \mathrm{M}$ of each drug for $48 \mathrm{~h}$.

The transient transfection was performed using the Lipofectamine 3000 (Invitrogen) reverse transfection protocol according to the manufacturer's instructions.

\section{Reagents and materials}

GAPDH (6c5), AR (N-20) antibodies, and PPAR $\gamma$ Antagonist III were purchased from Santa Cruz Biotechnology. PPAR $\gamma$, PDK1, PGC-1 $\beta$, and MMP-9 antibody were purchased from One World Lab. Anti-mouse/rabbit secondary antibody for Western Blot was from Invitrogen. Normal rabbit IgG was also from Santa Cruz Biotechnology. The PPAR $\gamma$-Antagonist III and Enz stock concentrations were $10 \mathrm{mM}$.

\section{Test of RNase $R$ resistance}

Total RNA was isolated by TRIZOL lysis followed by PureLink purification of the aqueous phase (Life Technologies). Total RNA at $2 \mu \mathrm{g}$ was treated in a $10-\mu$ l reaction with 0 units (mock treatment) or 20 units of RNase $\mathrm{R}$ (Epicentre) in $1 \times$ RNase $\mathrm{R}$ buffer, 1 -unit/ $\mu$ l murine Ribonuclease Inhibitor (New England Biolabs), and incubated at $37^{\circ} \mathrm{C}$ for $1 \mathrm{~h}$. Then $1 \mu \mathrm{l} 1$-mM EDTA, $1 \mu \mathrm{l} 10$-mM each $\mathrm{dNTP}$, and $1 \mu \mathrm{l} 100-\mu \mathrm{M}$ random hexamer were added and

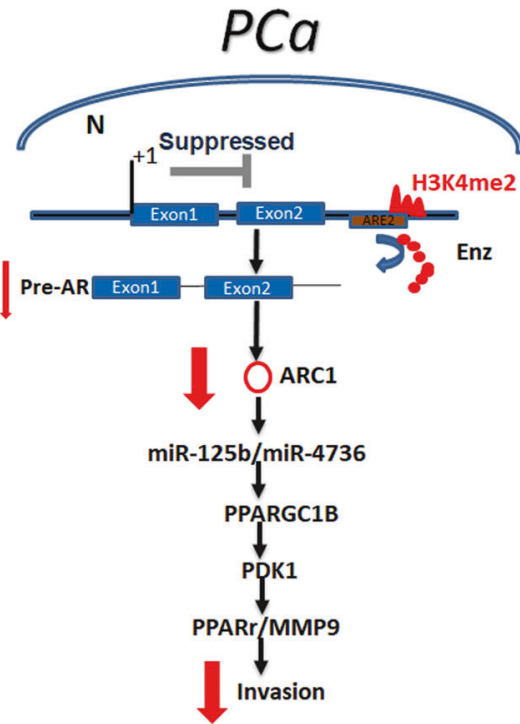

suppressing AR transcription. Enzalutamide (Enz) prevents AR from binding ARE1 in BCa and ARE2 in PCa. ARC1 increases the expression level of PPARGC1/PDK1/MMP-9 signaling by sponging miR-125b and miR-4736, leading to enhanced cell invasion. High level of $\mathrm{H} 3 \mathrm{~K} 4 \mathrm{me} 2$ serves as one biomarker of gene transcription activation. $\mathrm{N}$ nucleus.

the RNA denatured at $65^{\circ} \mathrm{C}$ for $5 \mathrm{~min}$ and placed on ice. Then 4- $\mu$ l 10X buffer $(250 \mathrm{mM}$ Tris- $\mathrm{HCl} / \mathrm{pH} 8,125 \mathrm{mM}$ $\mathrm{KCl}$, and $15 \mathrm{mM} \mathrm{MgCl}_{2}$ ), 1- $\mu$ l murine Ribonuclease Inhibitor (40 units/ $\mu \mathrm{l}$ ), and 1- $\mu \mathrm{l}$ Superscript III (Life Technologies) were added and this cDNA reaction was incubated at $25^{\circ} \mathrm{C}$ for $10 \mathrm{~min}, 50^{\circ} \mathrm{C}$ for $50 \mathrm{~min}, 55^{\circ} \mathrm{C}$ for $10 \mathrm{~min}$, and $85^{\circ} \mathrm{C}$ for $5 \mathrm{~min}$. Then $0.5-\mu \mathrm{l}$ cDNA reaction was used as the template for qPCR and fraction resistance was computed as $2^{\wedge}($ RNase R Ct - Mock Ct).

\section{CircRNA-ARC1 overexpression plasmid construction}

The pWPI-circARC1 was constructed by PCR amplifying the circRNA locus, including 1-kb upstream and 200-bp downstream to the nonlinear splice sites. The PCR fragment was amplified and ligated with Pme I + Pac I digested pWPI (Addgene) using the Gibson ligation system. PLKOshRNAs were constructed following the standard protocol. Briefly, oligos were annealed and ligated with EcoR I + Age I digested PLKO vector. The junction of circARC1 was used as a template to design shRNAs.

\section{Lentivirus packaging}

The pLVTHM-miR-125b-2-3p, pLVTHM-miR-4736, pLVTHM-miR-4725, pWPI-OE-ARC1, pLVTHM-shARC1, or pLKO.1-shAR, the psAX2 packaging plasmid, and pMD2G envelope plasmid were transfected into 293T cells using the standard calcium-chloride transfection method for 
$48 \mathrm{~h}$ to get the lentivirus supernatants. The lentivirus supernatants were collected and concentrated by density gradient centrifugation, then frozen in $-80^{\circ} \mathrm{C}$ for later use.

\section{RNA extraction, miRNA extraction, and reverse transcription and quantitative real-time PCR (qRT-PCR) analysis}

For RNA extraction, total RNAs were isolated using Trizol reagent (Invitrogen) and $1 \mu \mathrm{g}$ of total RNA was subjected to reverse transcription using Superscript III transcriptase (Invitrogen). The qRT-PCR was conducted using a Bio-Rad CFX96 system with SYBR green to determine the mRNA expression level of a gene of interest. Expression levels were normalized to the expression of TATA box binding protein TBP RNA. Primers used for genes of interest were listed in Supplementary Table S1. The miRNAs were also reversed transcribed from total RNA. Briefly, $1 \mu \mathrm{g}$ of total RNA was processed for poly A addition by adding 2 units of polymerase with 1-mM ATP in $1 \mathrm{x}$ RT buffer at $37^{\circ} \mathrm{C}$ for $20 \mathrm{~min}$ in $10-\mu \mathrm{l}$ volume, then adding 50 -pmol anchor primer to $11 \mu$, incubating at $65^{\circ} \mathrm{C}$ for $5 \mathrm{~min}$, then $4{ }^{\circ} \mathrm{C}$ for $2 \mathrm{~min}$. For the last step of cDNA synthesis, we added 2- $\mu$ l 5x RT buffer, $2 \mu \mathrm{l} 10-\mathrm{mM}$ dNTP, $1-\mu \mathrm{l}$ reverse transcriptase to total $20 \mu \mathrm{l}$, and incubated at $42^{\circ} \mathrm{C}$ for $1 \mathrm{~h}$. qRT-PCR was conducted using a Bio-Rad CFX96 system with Tagman probe to determine the miRNA expressions. Expression levels were normalized to the expression of 5s RNA and/or U6.

\section{Western blot analysis}

Cells were lysed in RIPA buffer, and proteins $(30 \mu \mathrm{g})$ were separated on 8-10\% SDS/PAGE gel and then transferred onto PVDF membranes (Millipore, Billerica, MA). After blocking membranes, they were incubated with appropriate dilutions of specific primary antibodies, and then incubated with horseradish peroxidase (HRP)-conjugated secondary antibodies and visualized using the ECL system (Thermo Fisher Scientific, Waltham, MA). The antibodies used were listed in Supplementary Table S2.

\section{Cell invasion assay}

The invasion capability of $\mathrm{PCa}$ and $\mathrm{BCa}$ cells was determined using the Transwell assay. Briefly, for invasion assay, before seeding the cells, $100 \mu \mathrm{l}$ of Matrigel (BD, Inc., Franklin Lakes, NJ.) was dissolved in $1.5-\mathrm{mL}$ serum-free DMEM and applied to upper chambers of 8$\mu \mathrm{m}$-pore-size polycarbonate membrane filters (Corning, Inc., Corning, NY), and the transwells were incubated at $37^{\circ} \mathrm{C}$ for $5 \mathrm{~h}$. Harvested cells were then seeded with serum-free media into the upper chambers at $1 \times 10^{5}$ cells/well, and the bottom chambers contained mixed conditioned media $(\mathrm{CM})$ with $10 \% \mathrm{FBS}$, and then incubated for $24 \mathrm{~h}$ at $37^{\circ} \mathrm{C}$. Following incubation, the invaded cells attached to the lower surface of the membrane were fixed by $4 \%$ paraformaldehyde and stained with $1 \%$ crystal violet. Cell numbers were counted in five randomly chosen microscopic fields (100x) per membrane.

\section{Luciferase Assay}

The human PPARGC1B/PDK1 3'UTR containing wild-type or mutant miRNA-responsive elements were cloned into the psiCHECK $^{\text {TM}}$-2 vector construct (Promega, Madison, WI) downstream of the Renilla luciferase ORF. Luciferase activity was measured by the Dual-Luciferase Assay (Promega) according to the manufacturer's manual.

\section{Chromatin Immunoprecipitation Assay (ChIP)}

Cells were cross-linked with $4 \%$ formaldehyde for $10 \mathrm{~min}$ followed by cell collection and sonication with a predetermined power to shear chromatin to 200-500-bp DNA fragments. Then, cell lysates were pre-cleared sequentially with normal rabbit IgG and protein A-agarose. Anti-PPAR $\gamma$ antibody was used for immunoprecipitation. For the negative control, IgG was used in the reaction. Specific primer sets were designed to amplify a target sequence within the human MMP-9 promoter, and PCR products were identified by agarose gel electrophoresis.

\section{Pull-down Assay}

The culture cells were lysed in RIPA lysis buffer (20-nM Tris$\mathrm{HCl} / \mathrm{pH} 7.5,150-\mathrm{mM} \mathrm{NaCl}, 1-\mathrm{mM} \mathrm{Na}_{2}$ EDTA, 1-mM EGTA, $1 \%$ NP-40, $1 \%$ sodium deoxycholate, 2.5 -mM sodium pyrophosphate, 1-mM beta-glycerophosphate, 1-mM $\mathrm{Na}_{3} \mathrm{VO}_{4}$, and $1-\mu \mathrm{g} / \mathrm{ml}$ leupeptin) supplemented with RNase inhibitor $(1.5 \mu \mathrm{l})$. The supernatant was incubated with $250 \mathrm{nM}$ of antisense oligos overnight at $4{ }^{\circ} \mathrm{C}$. Streptavidin Agarose beads were incubated with the supernatant for $2 \mathrm{~h}$. The complex was centrifuged at $3000 \mathrm{rpm}$, and the beads were washed five times with RIPA lysis buffer. The RNA was extracted using Trizol (Invitrogen) according to the manufacturer's protocol and subjected to RT-PCR analysis.

\section{CRISPR-dCAS9-mediated transcriptional regulation}

The cultured cells were first transfected with shAR and PWPI plasmid, then CRISPR-dCas9-CRAB plasmids and sgRNA targeting the host gene-AR expression vector were simultaneously infected into cells. The cells were harvested at $72 \mathrm{~h}$ after transfection. The RNA was extracted as above using Trizol (Invitrogen) according to the manufacturer's protocol and subjected to RT-PCR analysis. 


\section{In vivo studies}

Six-to-eight weeks old nude mice were purchased from NCI and divided into four treatment groups $(n=32$ for each group): (1) Vector (DMSO); (2) Enz; (3) pWPI + shARC1; and (4) Enz+shARC1. The transduced CWR22Rv1 cells suspended in media were mixed with Matrigel $(1: 1, \mathrm{v} / \mathrm{v})$ and injected into the anterior prostates $\left(1 \times 10^{6}\right.$ cells/AP) of these nude mice. Tumor development and metastasis were monitored by Luminescence Imager (IVIS Spectrum, Caliper Life Sciences, Hopkinton, MA) once a week. When the tumors become palpable 2 weeks after implantation, the shARC1 and vector mice were randomly assigned into two groups, respectively (32 mice per group), receiving various therapies by i.p. injection 3 times/wk/4 wks (Enz at $30 \mathrm{mg} / \mathrm{kg}$ or DMSO every other day). The mouse body weights were monitored weekly as well as tumors by the IVIS system for another 2-3 weeks. At the end of the treatment, mice were sacrificed and tumor growth and metastases at lymph nodes as well as to distant organs were analyzed. The animal experiments were approved and supervised by the University Committee on Animal Resource of University of Rochester Medical Center.

\section{H\&E and immunohistochemical (IHC) staining}

Tissues were fixed in $10 \%(\mathrm{v} / \mathrm{v})$ formaldehyde in PBS, embedded in paraffin, and cut into $4-\mu \mathrm{m}$ sections and used for $\mathrm{H} \& \mathrm{E}$ staining and IHC staining with specific primary antibodies against AR/MMP-9. To enhance antigen exposure, the slides were treated with $1 \times$ EDTA at $98^{\circ} \mathrm{C}$ for $10 \mathrm{~min}$ for antigen retrieval. The slides were incubated with endogenous peroxidase blocking solution, and then were incubated with the primary antibody at $4{ }^{\circ} \mathrm{C}$ overnight. After rinsing with Tris-buffered saline, the slides were incubated for $45 \mathrm{~min}$ with biotin-conjugated secondary antibody, washed, and then incubated with enzyme conjugate HRP-streptavidin. Freshly prepared DAB (Zymed, South San Francisco, CA) was used as substrate to detect HRP. Finally, slides were counterstained with hematoxylin and mounted with aqueous mounting media. Positive cells were calculated as the number of immunopositive cells $\times 100 \%$ divided by total number of cells/field in ten random fields at $\times 400$ magnification.

\section{Statistical analysis}

Data were expressed as mean \pm SEM from at least three independent experiments with each data point in triplicate. Statistical analyses involved the Tukey's test with SPSS 17.0 (SPSS Inc., Chicago, IL). Chi-square test was used to analyze the number of mice with metastases between two groups. Exact Fisher $t$-test was used to test the difference in metastatic foci numbers among the four groups of mice. Linear correlation analyses were performed to determine the correlation between the gene expression levels. $P<0.05$ was considered statistically significant.

Acknowledgements We thank Karen Wolf for help preparing the manuscript.

Author contributions CC and SM oversaw the study. GD, RW, YS, $\mathrm{SY}$, BY performed the experiments and wrote manuscript. CF provided statistical analysis. CH and GL provided some constructive suggestions.

Funding This work was supported in part by NIH grant CA156700 and George Whipple Professorship Endowment, China National Natural Science Foundation (81172072 and 81903113), Natural Science Foundation of Zhejiang Province (LY17H050002), and Taiwan Department of Health Clinical Trial and Research Center of Excellence grant (MOHW105-TDU-B-212-133019).

\section{Compliance with ethical standards}

Conflict of interest The authors declare no competing interests.

Ethics statement All experiments complied with URMC ethical Standards and the in vivo animal Studies protocols were approved by the URMC Department of Medicine.

Publisher's note Springer Nature remains neutral with regard to jurisdictional claims in published maps and institutional affiliations.

Open Access This article is licensed under a Creative Commons Attribution 4.0 International License, which permits use, sharing, adaptation, distribution and reproduction in any medium or format, as long as you give appropriate credit to the original author(s) and the source, provide a link to the Creative Commons license, and indicate if changes were made. The images or other third party material in this article are included in the article's Creative Commons license, unless indicated otherwise in a credit line to the material. If material is not included in the article's Creative Commons license and your intended use is not permitted by statutory regulation or exceeds the permitted use, you will need to obtain permission directly from the copyright holder. To view a copy of this license, visit http://creativecommons. org/licenses/by/4.0/.

\section{References}

1. Asangani IA, Dommeti VL, Wang X, Malik R, Cieslik M, Yang R, et al. Therapeutic targeting of BET bromodomain proteins in castration-resistant prostate cancer. Nature. 2014;510: 278-82.

2. Culig Z, Klocker H, Bartsch G, Hobisch A. Androgen receptors in prostate cancer. Endocr Relat Cancer. 2002;9:155-70.

3. Qin J, Lee HJ, Wu SP, Lin SC, Lanz RB, Creighton CJ, et al. Androgen deprivation-induced $\mathrm{NCoA} 2$ promotes metastatic and castration-resistant prostate cancer. J Clin Investig. 2014;124: 5013-26.

4. Niu Y, Chang TM, Yeh S, Ma WL, Wang YZ, Chang C. Differential androgen receptor signals in different cells explain why androgen-deprivation therapy of prostate cancer fails. Oncogene. 2010;29:3593-604. 
5. Chang CS, Kokontis J, Liao ST. Molecular cloning of human and rat complementary DNA encoding androgen receptors. Science. 1988;240:324-6.

6. Heinlein CA, Chang C. Androgen receptor in prostate cancer. Endocr Rev. 2004;25:276-308.

7. Miyamoto H, Yang Z, Chen YT, Ishiguro H, Uemura H, Kubota $\mathrm{Y}$, et al. Promotion of bladder cancer development and progression by androgen receptor signals. J Natl Cancer Inst. 2007;99: 558-68.

8. Hsu JW, Hsu I, Xu D, Miyamoto H, Liang L, Wu XR, et al. Decreased tumorigenesis and mortality from bladder cancer in mice lacking urothelial androgen receptor. Am J Pathol. 2013; 182:1811-20

9. He D, Li L, Zhu G, Liang L, Guan Z, Chang L, et al. ASC-J9 suppresses renal cell carcinoma progression by targeting an androgen receptor-dependent HIF2alpha/VEGF signaling pathway. Cancer Res. 2014;74:4420-30.

10. Song W, Li L, He D, Xie H, Chen J, Yeh CR, et al. Infiltrating neutrophils promote renal cell carcinoma (RCC) proliferation via modulating androgen receptor (AR) $->\mathrm{c}-\mathrm{Myc}$ signals. Cancer Lett. 2015;368:71-8.

11. Yeh S, Hu YC, Wang PH, Xie C, Xu Q, Tsai MY, et al. Abnormal mammary gland development and growth retardation in female mice and MCF7 breast cancer cells lacking androgen receptor. J Exp Med. 2003;198:1899-908.

12. Ma WL, Hsu CL, Wu MH, Wu CT, Wu CC, Lai JJ, et al. Androgen receptor is a new potential therapeutic target for the treatment of hepatocellular carcinoma. Gastroenterology. 2008; 135:947-55.e1-5.

13. Ma WL, Hsu CL, Yeh CC, Wu MH, Huang CK, Jeng LB, et al. Hepatic androgen receptor suppresses hepatocellular carcinoma metastasis through modulation of cell migration and anoikis. Hepatology. 2012;56:176-85.

14. Wu MH, Ma WL, Hsu CL, Chen YL, Ou JH, Ryan CK, et al. Androgen receptor promotes hepatitis B virus-induced hepatocarcinogenesis through modulation of hepatitis B virus RNA transcription. Sci Transl Med. 2010;2:32ra5.

15. Lin HK, Hu YC, Yang L, Altuwaijri S, Chen YT, Kang HY, et al. Suppression versus induction of androgen receptor functions by the phosphatidylinositol 3-kinase/Akt pathway in prostate cancer LNCaP cells with different passage numbers. J Biol Chem. 2003;278:50902-7.

16. Lin TH, Izumi K, Lee SO, Lin WJ, Yeh S, Chang C. Antiandrogen receptor ASC-J9 versus anti-androgens MDV3100 (Enzalutamide) or Casodex (Bicalutamide) leads to opposite effects on prostate cancer metastasis via differential modulation of macrophage infiltration and STAT3-CCL2 signaling. Cell Death Dis. 2013;4:e764.

17. Niu Y, Altuwaijri S, Lai KP, Wu CT, Ricke WA, Messing EM, et al. Androgen receptor is a tumor suppressor and proliferator in prostate cancer. Proc Natl Acad Sci USA. 2008; 105:12182-7.

18. Niu Y, Altuwaijri S, Yeh S, Lai KP, Yu S, Chuang KH, et al. Targeting the stromal androgen receptor in primary prostate tumors at earlier stages. Proc Natl Acad Sci USA. 2008;105:12188-93.

19. Hsieh TF, Chen CC, Ma WL, Chuang WM, Hung XF, Tsai YR, et al. Epidermal growth factor enhances androgen receptormediated bladder cancer progression and invasion via potentiation of AR transactivation. Oncol Rep. 2013;30:2917-22.

20. Salzman J, Gawad C, Wang PL, Lacayo N, Brown PO. Circular RNAs are the predominant transcript isoform from hundreds of human genes in diverse cell types. PloS ONE. 2012;7:e30733.

21. Wapinski O, Chang HY. Long noncoding RNAs and human disease. Trends Cell Biol. 2011;21:354-61.

22. Rybak-Wolf A, Stottmeister C, Glazar P, Jens M, Pino N, Giusti $\mathrm{S}$, et al. Circular RNAs in the mammalian brain are highly abundant, conserved, and dynamically expressed. Mol Cell. 2015; 58:870-85.

23. Hansen TB, Jensen TI, Clausen BH, Bramsen JB, Finsen B, Damgaard CK, et al. Natural RNA circles function as efficient microRNA sponges. Nature. 2013;495:384-8.

24. Memczak S, Jens M, Elefsinioti A, Torti F, Krueger J, Rybak A, et al. Circular RNAs are a large class of animal RNAs with regulatory potency. Nature. 2013;495:333-8.

25. Lin TH, Lee SO, Niu Y, Xu D, Liang L, Li L, et al. Differential androgen deprivation therapies with anti-androgens casodex/ bicalutamide or MDV3100/Enzalutamide versus anti-androgen receptor ASC-J9(R) Lead to promotion versus suppression of prostate cancer metastasis. J Biol Chem. 2013;288:19359-69.

26. Vincent HA, Deutscher MP. Substrate recognition and catalysis by the exoribonuclease RNase R. J Biol Chem. 2006;281:29769-75.

27. Danan M, Schwartz S, Edelheit S, Sorek R. Transcriptome-wide discovery of circular RNAs in Archaea. Nucleic Acids Res. 2012;40:3131-42.

28. Mandegar MA, Huebsch N, Frolov EB, Shin E, Truong A, Olvera MP, et al. CRISPR interference efficiently induces specific and reversible gene silencing in human iPSCs. Cell Stem Cell. 2016;18:541-53.

29. Lukiw WJ. Circular RNA (circRNA) in Alzheimer's disease (AD). Front Genet. 2013;4:307.

30. Hansen TB, Kjems J, Damgaard CK. Circular RNA and miR-7 in cancer. Cancer Res. 2013;73:5609-12.

31. Banzhaf-Strathmann J, Edbauer D. Good guy or bad guy: the opposing roles of microRNA $125 \mathrm{~b}$ in cancer. Cell Commun Signal. 2014;12:30.

32. Gao Q, Yao X, Zheng J. MiR-323 inhibits prostate cancer vascularization through adiponectin receptor. Cell Physiol Biochem. 2015;36:1491-8.

33. Lian HW, Zhou Y, Jian ZH, Liu RZ. MiR-323-5p acts as a tumor suppressor by targeting the insulin-like growth factor 1 receptor in human glioma cells. Asian Pac J Cancer Prev. 2014;15:10181-5.

34. Zou MX, Huang W, Wang XB, Lv GH, Li J, Deng YW. Identification of miR-140-3p as a marker associated with poor prognosis in spinal chordoma. Int J Clin Exp Pathol. 2014;7:4877-85.

35. Ru Y, Kechris KJ, Tabakoff B, Hoffman P, Radcliffe RA, Bowler $\mathrm{R}$, et al. The multiMiR $\mathrm{R}$ package and database: integration of microRNA-target interactions along with their disease and drug associations. Nucleic Acids Res. 2014;42:e133.

36. Zhu J, Wang S, Zhang W, Qiu J, Shan Y, Yang D, et al. Screening key microRNAs for castration-resistant prostate cancer based on miRNA/mRNA functional synergistic network. Oncotarget. 2015; 6:43819-30.

37. Li CC, Hou YC, Yeh CL, Yeh SL. Effects of eicosapentaenoic acid and docosahexaenoic acid on prostate cancer cell migration and invasion induced by tumor-associated macrophages. PLoS ONE. 2014;9:e99630.

38. Wang Y, Tan H, Xu D, Ma A, Zhang L, Sun J, et al. The combinatory effects of PPAR-gamma agonist and survivin inhibition on the cancer stem-like phenotype and cell proliferation in bladder cancer cells. Int J Mol Med. 2014;34:262-8.

39. Yan S, Yang X, Chen T, Xi Z, Jiang X. The PPARgamma agonist Troglitazone induces autophagy, apoptosis and necroptosis in bladder cancer cells. Cancer Gene Ther. 2014;21:188-93.

40. Yang DR, Lin SJ, Ding XF, Miyamoto H, Messing E, Li LQ, et al. Higher expression of peroxisome proliferator-activated receptor gamma or its activation by agonist thiazolidinedione-rosiglitazone promotes bladder cancer cell migration and invasion. Urology. 2013;81:1109.e1-6.

41. Siegel RL, Miller KD, Jemal A. Cancer statistics, 2017. CA: Cancer J Clin. 2017;67:7-30.

42. Chen W. Cancer statistics: updated cancer burden in China. Chin J Cancer Res = Chung-kuo Yen Cheng Yen Chiu. 2015;27:1. 
43. Dobruch J, Daneshmand S, Fisch M, Lotan Y, Noon AP, Resnick $\mathrm{MJ}$, et al. Gender and bladder cancer: a collaborative review of etiology, biology, and outcomes. Eur Urol. 2016;69:300-10.

44. Chang C, Lee SO, Yeh S, Chang TM. Androgen receptor (AR) differential roles in hormone-related tumors including prostate, bladder, kidney, lung, breast and liver. Oncogene. 2014;33: 3225-34.

45. Capel B, Swain A, Nicolis S, Hacker A, Walter M, Koopman P, et al. Circular transcripts of the testis-determining gene Sry in adult mouse testis. Cell. 1993;73:1019-30.

46. Ebert MS, Neilson JR, Sharp PA. MicroRNA sponges: competitive inhibitors of small RNAs in mammalian cells. Nat Methods. 2007;4:721-6.

47. Franco-Zorrilla JM, Valli A, Todesco M, Mateos I, Puga MI, Rubio-Somoza I, et al. Target mimicry provides a new mechanism for regulation of microRNA activity. Nat Genet. 2007;39:1033-7.

48. Poliseno L, Salmena L, Zhang J, Carver B, Haveman WJ, Pandolfi PP. A coding-independent function of gene and pseudogene mRNAs regulates tumour biology. Nature. 2010;465:1033-8.

49. Liu Y, Cui H, Wang W, Li L, Wang Z, Yang S, et al. Construction of circular miRNA sponges targeting miR-21 or miR-221 and demonstration of their excellent anticancer effects on malignant melanoma cells. Int J Biochem Cell Biol. 2013;45:2643-50.

50. Cai C, He HH, Chen S, Coleman I, Wang H, Fang Z, et al. Androgen receptor gene expression in prostate cancer is directly suppressed by the androgen receptor through recruitment of lysine-specific demethylase 1. Cancer Cell. 2011;20:457-71.

51. Singh A, Figg WD. Upregulation of the androgen receptor during prostate cancer progression. Cancer Biol Ther. 2004;3:284-5.

52. Arora VK, Schenkein E, Murali R, Subudhi SK, Wongvipat J, Balbas MD, et al. Glucocorticoid receptor confers resistance to antiandrogens by bypassing androgen receptor blockade. Cell. 2013;155:1309-22.

53. Chari R, Mali P, Moosburner M, Church GM. Unraveling CRISPR-Cas9 genome engineering parameters via a library-onlibrary approach. Nat Methods. 2015;12:823-6.

54. Izumi K, Taguri $M$, Miyamoto $H$, Hara $Y$, Kishida $T$, Chiba K, et al. Androgen deprivation therapy prevents bladder cancer recurrence. Oncotarget. 2014;5:12665-74.

55. Robinson D, Van Allen EM, Wu YM, Schultz N, Lonigro RJ, Mosquera JM, et al. Integrative clinical genomics of advanced prostate cancer. Cell. 2015;161:1215-28. 